\title{
COLECISTECTOMIA VÍDEO-LAPAROSCÓPICA EM SUÍNOS
}

\author{
VÍDEO-LAPAROSCOPIC CHOLECYSTECTOMY IN SWINE
}

\author{
Marcelo Alves Pinto* Cláudio Corrêa Natalini** Ghendy Cardoso***
}

\section{RESUMO}

Dezoito suínos foram submetidos experimentalmente a colecistectomia vídeo-laparoscópica. Neste experimento procurou-se padronizar e avaliar a técnica cirúrgica e anestésica para sua utilização em centros de treinamento em cirurgia experimental, bem como de terapêutica cirúrgica em medicina veterinária.

Palavras-chave: colecistectomia, vídeo-laparoscopia, laparoscopia em suínos.

\section{SUMMARY}

Eighteen pigs were submitted to experimental video-laparoscopic cholecistectomy. In this study the surgical and anesthetic procedure were standarized and evaluated in order to use in training experimental surgical centers and as surgical therapeutics in veterinary medicine.

Key words: cholecistectomy, video-laparoscopy, laparoscopy in swine.

\section{INTRODUÇĀO}

Com o surgimento de diversos centros de treinamento em cirurgia vídeo-laparoscópica no país, atentou-se à necessidade de adaptação técnica e padronização desta, para seu emprego experimental em suínos e para a prática clínica cirúrgica em medicina-veterinária.

GAZZANIGA et al (1976), consideram a laparoscopia um principal meio diagnóstico para lesōes penetrantes no abdome, em indivíduos comatosos.

CORTESI et al (1979) e SLATTER (1985), rela- taram o uso de laparoscpia para pequenos procedimentos cirúrgicos como biópsias hepáticas, renais, pancreáticas, esplênicas e prostáticas, em cães e para manipulações reprodutivas em animais de grande porte.

SEMM(1983), descreveu pela primeira vez a técnica de sutura e cauterização endoscópia em apendicectomias humanas.

MEYERS et al (1991), comprovaram a baixa incidência de complicações no pós-operatório de colecistectomias, apesar da técnica provocar maior índice de traumatismos na vesicula biliar durante o procedimento.

LEBOWITZ et al (1982) afirmam serem comuns numerosas complicaçōes anestésicas em pacientes submetidos a laparoscopias. A maioria destas complicações estão relacionadas as alterações mecânicas e farmacológicas causadas pelos gases utilizados para a obtenção do pneumo-peritônio. Estes autores citam o fato do emprego de variadas técnicas anestésicas em procedimentos laparoscópicos, sendo no entanto recomendada a anestesia geral com ventilação controlada. O protocolo descrito inclui o diazepam, indução com tiopental sódico e succinil-colina e manutenção com halogenados ou fentanil e oxido nitroso.

THURMON \& BENSON (1987), recomendam fármacos para a sedação e tranquilização em suínos como as butirofenonas, derivados tiazínicos, fenotiazinas e benzodiazepínicos. Dentre os derivados fenotiazínicos a acepromazina é a mais utilizada clinicamente. O diazepan é - derivado benzodiazepínico de eleição em suínos, em doses elevadas de $8,5 \mathrm{mg} / \mathrm{kg}$. Nesta dose, citam os autores, obtem-se excelente sedação.

MUIR \& HUBBELL (1989), citam as combinaçōes atropina, xilazina, cetamina e tiletamina, zolazepam e xilazina para indução anestésica em suínos, sendo necessária a manutenção com agentes voláteis para obtenção de anestesia geral. Estes autores recomendam o isoflurano ou halotano, salientando que determinadas raças podem desenvolver hipertermia com o uso do halotano.

FONDA \& VANOSI (1991), descreveram um pro-

\footnotetext{
* Bolsista recém-mestre da FAPERGS, junto ao Departamento de Clínica de Pequenos Animais (DCPA), Universidade Federal de Santa Maria (UFSM). 97119-900 Santa Maria,RS

* Médico Veterinário, Mestre, Professor Assistente do DCPA.

*** Médico Veterinário, Doutor, Professor Titular do DCPA.
} 
tocolo de anestesia geral em suínos, com a utilização de bloqueio neuromuscular com brometo de pancurônio. Nesta técnica os autores empregaram a combinaçāo atropina, xilazina e cetamina por via intramuscular como forma de obtenção de indução anestésica. A intubação endotraqueal foi realizada com a administração de isoflurano por máscara e brometo de pancurônio venoso.

Os objetivos deste estudo visaram estabelecer critérios para o emprego da cirurgia vídeo-laparoscópica experimental em suínos e determinar um protocolo de anestesia geral com bloqueio neuromuscular e ventilação artificial nesta espécie. Foi também objeto de estudo a observação das complicaçōes pós-laparoscopia.

\section{MATERIAL E MÉTODOS}

\section{1- Técnica Anestésica}

Foram utilizados dezoito suínos da raça "Large White", machos ou fêmeas, de 15 a $20 \mathrm{~kg}$ de peso. Estes estiveram sob jejum pré-operatório de 12 horas para dieta sólida e sem restrição para líquidos.

Foi realizada sedação com a associação do cloridrato de levomepromazina $1 \mathrm{mg} / \mathrm{kg}$ e cloridrato de midazolamb $0,5 \mathrm{mg} / \mathrm{kg}$, via intramuscular.

Após quinze (15) minutos da administração da associação sedativa foi procedida a cateterização venosa, na veia marginal da orelha direita com catéter apropriado $^{c}$ e iniciada a infusão de soluçāo de Ringer com lactato de sódio na dose de $10 \mathrm{ml} / \mathrm{kg} /$ hora. Através do catéter venoso administrou-se tiopental sódico ${ }^{d}$ na dose de $10 \mathrm{mg} / \mathrm{kg}$. Em seguida os suinos tiveram suas traquéias intubadas.

Na manutenção anestésica empregou-se o halotano ${ }^{e}$ na concentração de $1,5 \mathrm{~V} \%$ em sistema semi-aberto com respiração controlada por respirador mecânico pressométricơ. A freqüência respiratória foi determinada como 15 ciclos por minuto com pressão de admissão de $15 \mathrm{~cm}$ de $\mathrm{H}_{2} \mathrm{O}$. Como relaxante muscular foi utilizado o brometo de pancurônio", na dose de $0,05 \mathrm{mg} / \mathrm{kg}$ via venosa.

\section{2 - Técnica Operatória}

Sob anestesia geral os suínos foram encaminhados ao bloco cirúrgico do centro de treinamento em vídeo-laparoscopia do Hospital Central do Exército, no Rio de Janeiro, onde procedeu-se 0 ato operatório.

$\mathrm{Na}$ obtenção do pneumo-peritônio a cavidade abdominal foi puncionada com agulha de Verres, na região da cicatriz umbilical, após pequena incisão cutânea.

$\mathrm{O} \mathrm{CO}_{2}$ foi empregado para insuflação da cavidade abdominal com pressão de $7-8 \mathrm{mmHg}$, e 0 ato cirúrgico realizado com instrumental apropriado.
A colocação dos trocartes foi realizada de acordo com a localização anatômica da vesícula biliar no suíno. O primeiro trocarte de $10 \mathrm{~mm}^{\mathrm{h}}$ de diâmetro foi inserido a $2 \mathrm{~cm}$ à direita da linha média entre a cartilagem xifóide e a cicatriz umbilical. Os trocartes secundários de $5 \mathrm{~mm}$ de diâmetro foram inseridos no terço proximal da linha média xifo-umbilical e paralelamente a cicatriz umbilical, $2 \mathrm{~cm}$ à direita da linha portal.

Os vasos epigástricos foram evitados durante a punção devido a iluminação trans-abdominal fornecida pelo laparoscópioj.

Após identificação da vesícula biliar, afastaramse os lóbulos hepáticos e por tração na porção caudal do orgão, foi exposto o ducto biliar. Com o fórcepes de dissecçãd identificaram-se a artéria e veia cística que foram clipadas por fórcepes adequadó e seccionadas. O mesmo procedimento foi desenvolvido para o ducto cístico.

A vesícula foi tracionada pelo infundíbulo e dissecada pelo leito hepático com uso de uma alça de cauterização. Após dissecado, o órgão foi extraído pelo trocarte de $10 \mathrm{~mm}$ e as ligaduras inspecionadas.

Desfeito o pneumo-peritônio por aspiração, os orifícios foram fechados em planos com fio de nailon monofilamento $3-0^{m}$.

\section{RESULTADOS}

A técnica anestésica mostrou-se adequada para o procedimento, sem intercorrências dignas de nota. Em três suínos nos quais iniciou-se a insuflação intra-abdominal com $\mathrm{CO}_{2}$ a $9 \mathrm{mmHg}$, sem estar instituída a ventilação por pressã̃o positiva intermitente, observou-se cianose.

A associação sedativa tornou facilitada a manipulação dos suínos, com relaxamento dos animais e realização da punção venọsa sem dificuldades.

O procedimento da cavidade abdominal com $\mathrm{CO}_{2}$ permitiu uma ampla separação da parede do abdome da superfície visceral. A resistência ao aumento da pressão intra-abdominal é tolerada pelo suíno até a pressão de $8 \mathrm{mmHg}$.

Um dos suínos desenvolveu um estado de choque no pós-operatório imediato. Procedeu-se a laparotomia tradicional, com a constatação de hemorragia difusa na superfície cruenta do fígado.

Dois animais desenvolveram enfisema subcutâneo nos locais de punção, que foram drenados sem complicações.

Em um dos suínos diagnosticou-se sinais de infecção pós-operatória, com presença de peritonite e óbito. À necropsia constatou-se a presença de conteúdo purulento cavitário e intensa aderência do grande omento com a superfície hepática. 


\section{DISCUSSÃO}

O emprego da vídeo-laparoscopia surge como opção para o diagnóstico e tratamento de patologias em medicina veterinária e humana. No decorrer deste treinamento atentou-se para algumas consideraçōes importantes, como a obtençāo de pneumo-peritônio com a ocorrência de hipoventilação. Esta observação pode ser explicado pelo que afirmam GAZZANIGA et al (1976).

A cirurgia laparoscópica mostrou ser um método seguro e apropriado à colecistectomia em suínos, proporcionando um pós-operatório sem manifestação de dor após a recuperação anestésica. Este fator foi citado por CORTESI et al (1979) como grande vantagem da cirurgia laparoscópica, aliada a simplicidade do procedimento e a necessidade de se conhecer a anatomia normal e patológica dos orgãos sob a ótica da laparoscopia.

As complicaçōes encontradas como contaminação da cavidade e hemorragia local são descritas por MEYERS et al (1991), sugerindo a cirurgia convencional como método de correção das intercorrências cirúrgicas. Neste estudo lançou-se mão desta orientação no caso do animal que apresentou hemorragia na superfície hepática no pós-operatório.

A observação de aderências no leito vesicular, através da migração omental, não coincide com as afirmações de SEMM (1983) de que a técnica de laparoscopia reduz as possibilidades de aderência pós-operatória.

A utilização de ventilação por pressão positiva intermitente está indicada quando da utilização de $\mathrm{CO}_{2}$ como gás na obtenção do penumo-peritônio, como citado por GAZZANIGA et al (1976) e por LEBOWITZ et al (1882). Esta técnica permite não somente a adequada eliminação do $\mathrm{CO}_{2}$ sangüíneo, mantendo a $\mathrm{PaCO}_{2} \mathrm{em}$ níveis aceitáveis, como também evitando a hipoventilação por aumento da pressão intra-abdominal. Neste estudo os dados obtidos permitem concordar com estas observaçōes de vez que alguns animais tornaram-se cianóticos quando foi insuflado $\mathrm{CO}_{2}$ na cavidade abdominal sem prévio início da respiração artificial.

Os derivados fenotiazínicos são utilizados amplamente na prática clínica com suínos. Quando empregados em doses elevadas podem causar hipotensão acentuada. Desta forma, a associação farmacológica de derivados fenotiazínicos e benzodiazepínicos, permite uma redução nas doses de ambos os fármacos, minimizando o risco de reações adversas. Esta combinação confere adequada sedação e relaxamento como foi observado neste estudo, estando em concordância com o que afirmam THURMON \& BENSON (1987).

MUIR \& HUBBEL (1989), afirmam que o protocolo anestésico incluindo atropina, acepromazina e tiamilal sódico, apresenta a desvantagem de produzir de- pressão respiratória e dificultar a punção venosa. Neste estudo, o adequado relaxamento muscular obtido no período de sedação, permitiu a punção venosa sem dificuldades, sugerindo ser a técnica uma opção vantajosa em relação a citada pelos autores. Após a indução com tiopental sódico, não foram observados episódios de apnéia ou depressão respiratória acentuada. Este fato permite concluir ser a técnica de indução anestésica utilizada neste estudo, destituída de efeitos adversos nesta espécie.

De acordo com o que afirmam THURMON \& BENSON (1987), a intubação orotraqueal é bastante dificultada em suínos, não somente pela angulação laríngea, como também pelo reduzido diâmetro traqueal nesta espécie, como citam MUIR \& HUBBELL (1989), a dificuldade encontrada para intubação traqueal dos suínos deste experimento, acordam com o descrito pela literatura.

Embora os procedimentos diagnósticos por laparoscopias possam ser realizados sob sedação e anestesia local infiltrativa, as cirurgias laparoscópicas que envolvam ressecção e incisão visceral exigem anestesia geral (LEBOWITZ et al, 1982). FONDA \& VANOSI (1991), relatam que 0 emprego de brometo de pancurônio e a manutenção com agentes voláteis, produzem relaxamento abdominal desejável durante 0 ato operatório. Nos animais utilizados neste estudo, foi possível observar esta característica de relaxamento, possivelmente em razão da manutenção anestésica com halotano associada ao bloqueio neuromuscular do brometo de pancurônio.

\section{CONCLUSÕES}

A cirurgia vídeo-laparoscópica mostra-se eficaz para colecistectomais em suínos, certificando ser uma técnica segura quando se obtém adequado treinamento da equipe cirúrgica.

A insuflação abdominal com $\mathrm{CO}_{2}$ por pressão acima de $8 \mathrm{mmHg}$, produz hipoventilação no suíno, exigindo respiração por pressão positiva intermitente.

A técnica de anestesia geral com levomepromazina, midazolam, tiopental sódico, halotano e pancurônio é adequado à cirurgia vídeo-laparoscópica em suínos.

\section{FONTES DE AQUISIÇĀO}

\footnotetext{
a - Neozine, Rhodia Laboratórios S.A. Sāo Paulo, SP.

b - Dormonid, Roche Laboratórios S.A. São Paulo, SP.

c - Insyte, Becton Dickinson Vascular Access Sandy, Utah, USA.

d - Thiopental, Cristália Produtos Quím. e Farm. Ltda. Itapira, SP.

e - Halotano, Cristália Prod. Quím. e Farm. Ltda. Itapira, SP.

f - Narcomatic, Narcosul Apar. Científicos S.A. Porto Alegre. RS.

g - Pancuron, Cristália Prod. Quím. e Farm. Ltda. Itapira, SP.

h - Endopath, Ethicon Johnson \& Johnson. São José dos Campos, SP.
} 
i - Straight Telescope, Karl Storz-Hopkins. Tuffingen, West Germany.

j - Dissection forceps, Karl Storz Operating Thoracoscope. Tufflingen, West Germany.

I - Endoclip, Ethicon Johnson \& Johnson. São José dos Campos, SP.

m - Mononylon 3-0 Ethicon Johnson \& Johnson. São José dos Campos, SP.

\section{REFERÊNCIAS BIBLIOGRÁFICAS}

COORTESI, N., ZAMBARDA, E., MANETI, I. et al. Laparoscopy in routine and emergency surgery. Am J Surg v. 137, p. $647-649,1979$.

FONDA, D., VANOSI, G. Anesthesia for swine liver transplantation: preliminary protocol. In: INTERNATIONAL CONGRESS OF VETERINARY ANAESTHESIA. 1991, Utrecht, Netherland. Resumos ... Utrecht, State University of Utrecht, 1991. p. 287. 411 p.

GAZZANIGA, A., STANTON, N., BARTIETY, R. Laparocopy in the diagnosis of blunt and penetrating injuries to the abdomen. Am $J$ Surg, v. 131, $p$. 315-318, 1976.

LEBOWITZ, P. W., NEWBERG, L., GILLETTE, M. Clinical anesthesia procedures of the Massachusetts General Hospital 2. ed. Boston: Little, Brown and Company, 1982. $597 \mathrm{p}$.

MEYERS, W.C., BRANUM, G.D., FAROUK, M. A perspective analysis of 1518 laparoscopic colecistectomies. New En J Med, v. 324, n. 16, p. 1073-1078, 1991.

MUIR, W.W., HUBBELL, J.A.E. Handbook of veterinary anesthesia. ST. Louis: Mosby, 1989. $340 \mathrm{p}$.

SEMM. L. Endoscopic appendicectomy. Endoscopy, v. 15, p. 59-64, 1983.

SLATTER, D.H. Textbook of small animal surgery. Philadelphia: Saunders, 1985. V. 1, cap. 28.2718 p.

THURMON, J.G., BENSON, J.G. Special anesthesia consideration of swine. In: SHORT, C.E. Principle and practice of veterinary anesthesia. Baltimore: Williams \& Wilkins, 1987. p. 308-332. 